\title{
Exploring British Pakistani mothers' perception of their child with disability: insights from a UK context
}

\section{Article}

in

Journal of Research in Special Educational Needs

April 2017

This is an Accepted Manuscript of an article published in Journal of Research in Special Educational Needs in April 2017, available online: doi:10.1111/1471-3802.12111

To cite this article: Rizvi, S. (2017), Exploring British Pakistani mothers' perception of their child with disability: insights from a UK context. Journal of Research in Special Educational Needs, 17: 87-97. doi:10.1111/1471-3802.12111 


\title{
Exploring British Pakistani mothers' perception of their child with disability: insights from a UK context
}

\section{Sana Rizvi}

Graduate School of Education, University of Bristol

\begin{abstract}
This research lends insight into disabling discourses on South Asian families of children with disabilities. It explores immigrant Pakistani maternal understanding of their children's disability, uniquely through an educational perspective, highlighting maternal roles which schools must acknowledge to improve outcomes for children. The findings of this research, supported by a literature review, highlight various ideological threads shaping maternal understanding of disability and their children's schooling experiences. Data were collected through multiple case studies of immigrant Pakistani mothers of disabled children at Westchester School, incorporating semi-structured interviews and reviewing pupils' school files. After a process of open coding, the main themes emerging from interviews suggested maternal perceptions of disability evolved from a medicalised lens, onto identifying with structural barriers to children's progress, and a gendered lens. Both maternal perceptions and their professional interactions determined maternal accounts of their children's schooling experiences. This research highlights positive familial factors shaping maternal understanding of disability, supporting further studies into maternal advocacy and empowerment within UK special education.
\end{abstract}

Key words: Pakistani immigrant mothers, disability, religion, gender, educational placement. 


\section{Introduction}

The UK education system has transformed how it addresses children's disability in recent decades. There is no singularly accepted definition of disability within the UK (Feiler et al., 2012). Disability can be defined as structures, organisations and attitudes preventing people with impairment living to their full potential. Disability can also be defined in pathological terms, intrinsic to an individual's experience. However, this paper uses Shakespeare's (2008) interactive perspective of disability of multiple causes, some related to context and some specific to the individual and an intermeshing of the two. The Warnock (1978) Report and the Education Act 1981 [Department for Education and Science (DES, 1981)] introduced statutory requirements for local authorities (LAs) to assess children with disability or special education needs (SEN), and provide suitable provisions based on these assessments. The Education Act 1981 [Department for Education and Science (DES, 1981)] promoted parental advocacy, giving legal rights of appeal if parents disagreed with the provisions provided. In 1994, this legal right was strengthened through Special Education Needs and Disability Tribunals (SENDisT), an independent body set-up to resolve disputes between LAs and parents. Since then, further policies have been introduced like the SEN Code of Practice [Department for Education and Employment, 1994; Department for Education and Skills (DfES, 2001)] and the Draft SEN Code of Practice (Department for Education, 2012) taking effect in 2014 aiming to promote 'greater choice and control for young people and parents over their decision-making and support' (Department for Education, 2012, pp. 12).

Despite positive moves towards parental empowerment, insufficient research exists on ethnicminority (specifically South Asian) familial experiences of UK SEN provisions, how they comprehend their children's disability and navigate often conflicting SEN structures. Studies of 
South Asian disabled families, mostly conducted through health or social lenses, show poor experiences of provisions and lower service uptake (Croot et al., 2008; Hatton et al., 2004). However, these UK studies have not explored South Asian familial understanding of their children's SEN or the SEN provisions available.

Exploring South Asian maternal understanding of disability and their roles within assessment and school placement is critical, because Pakistani and Bangladeshi pupils are over-represented within profound multiple learning difficulties and sensory impairment categories (Strand and Lindsay, 2009). Moreover, over half of Pakistani and Bangladeshi households live in income poverty (Kenway and Palmer, 2007), precipitating more ethnic-minority pupils on Free School Meals which is a SEN identifier (Strand and Lindsay, 2009). Studies also show material deprivation and institutional racism engenders mistrust between South Asian families and service providers (Fazil et al., 2002; Scope and Equalities National Council, 2012).

Shah (1995), in her study of 35 South Asian families, found some health and social services professionals incorrectly assumed South Asians were homogenous. She suggests professionals should appreciate familial individuality to avoid misunderstandings, and advocates culturally sensitive services like professional interpreters. Numerous recent studies on South Asian families conducted from health and social justice perspectives suggest experiences of accessing provisions have not changed (Bywaters et al., 2003; Croot et al., 2008; Hatton et al., 2004; Scope and Equalities National Council, 2012). For instance, Hatton et al. (2004) found in their mixed-method study of 136 South Asian families, longer and ineffective disclosure for South Asian children compared to White British children. They also suggested a lack of same-sex carers explained lower South Asian uptake of formal care. Poor experiences of health and social services, implies that 
South Asian families may also have had similar experiences within educational institutions, although this claim requires investigation and validation.

Crozier and Davies (2006), Crozier (2009), Bhatti (1999) and Abbas (2004) have all explored experiences of South Asian typical families within the UK education system. Although they eschewed disability, these studies have nevertheless contextualised migrant history and adaptation to the mainstream. For instance, Crozier (2009) suggests transnational marriages are common within South Asian communities, which influences parental beliefs, knowledge and experience of the UK educational system. Bhatti (1999) and Abbas (2004) both noted a majority of Pakistani and Bangladeshi families live within encapsulated communities ${ }^{1}$, with strong extended family support. Crozier and Davies (2006), in their large-scale qualitative study of 157 Pakistani and Bangladeshi families and extended families, found strong family and community ties meant that schools classified the contributions of extended families as parental involvement. They suggest close community ties enhance the wealth of information and social capital available to parents, and should be utilised by schools to improve participation. The study by Crozier and Davies (2006) is theoretically similar to Gonzales, Moll and Amanti (2005), a US-based study exploring how Mexican parents and families helped develop classroom practices by sharing their social and intellectual knowledge. Interestingly, although Crozier and Davies (2006) view close community bonds as a positive resource, Abbas (2004) suggests such bond pre-vents South Asian families from adapting to mainstream culture, limiting their social mobility.

South Asian family literature disagrees about whether extended families are a source of support. Extended family and community ties played a strong role in the day-to-day lives of South Asian

\footnotetext{
${ }^{1}$ Bhatti (1999) describes these as closed-knitted communities where families interaction a daily basis with their community members, schools, grocery shops, local surgeries, thereby reducing the need and opportunities to interact with other ethnicities.
} 
typical families (Abbas, 2004; Bhatti, 1999; Crozier and Davies, 2006). However, a majority of South Asian families who cared for a family member with disability indicated no support from extended family net-works, and felt like a minority within a minority being stigmatised by community attitudes towards disability (Hatton et al., 2004; Katbamna et al., 2004). Most studies on South Asian typical families found that parents valued their child's education but were still decoding the UK education system. This process of decoding was further complicated when parents were also expected to understand how to use the SEN framework to enable better outcomes for their children.

This paper posits that the stereotype of South Asian dis-abled families reporting lower uptake of formal services because they 'look after their own' (Katbamna et al., 2004), has been derived from findings of strong community ties within South Asian typical families. Katbamna et al. (2004) also dispute that South Asian disabled families experience strong informal networks.

\section{Multidimensional contexts}

South Asian maternal roles and understanding are influenced by multiple realities such as culture, religion, language and migration history intersecting with macro-factors like health and immigration policy. These intersectionalities suggest ethnic-minority experiences are contextually different from White British disabled families (Heer, Rose and Larkin, 2012). Shah (1995) suggests South Asian literature corrals misunderstandings and barriers under religio-cultural and language factors, discarding other macro-level factors. For instance, following $9 / 11$ and $7 / 7^{2}$ subsequent anti-terror legislation and resultant Islamophobia have left British Muslims feeling

\footnotetext{
${ }^{2}$ 9/11 refers to attacks by Islamist terrorists belonging to Al-Qaeda on 11 September 2001, in New York City, Washington, DC and Pennsylvania. 7/7 refers to a series of coordinated terrorist attacks on London's transport system on 7 July 2005 by home-grown Islamist terrorists, inspired by Al-Qaeda.
} 
isolated; since two thirds of British Muslims are South Asian, Islam is a signifier affecting experiences of the other (Abbas, 2007).

Bywaters et al. (2003), Hatton et al. (2004) and Croot et al. (2008) all recognised the role of religion within South Asian understanding of disability, however, this is often confused with how religion influences parenting. This is significant because focusing on negative religious explanations of dis-ability marginalises parental effort. Parents perceived that supporting their disabled child brought spiritual closeness to God, while simultaneously expressing the real challenges involved (Hatton et al., 2004). Judaeo-Christian theology also links parenting disabled children with religion (Godina, 2012). Gottlieb (2002), a Jewish advocate and father to a disabled child, suggests parents risk becoming embittered to the disability experience without spirituality, notwithstanding the considerable time and money also involved. South Asian maternal understanding of disability must also be examined in light of migration history. Pakistanis and Bangladeshis first migrated to the UK in the 1960s and 1980s, respectively, and still constitute among the largest groups of new migrants annually (Blinder, 2012). Despite large established communities, South Asians still experience greater poverty and exclusion in employment, health and education than White British families (Kenway and Palmer, 2007). Although migrants value education, it is secondary to fulfilling primary needs or an uncertain immigration status (Arai, 2005). Despite the recent political focus on immigration, the formal service uptake remains low among migrants (Ward, Amas and Lagnado, 2008). Nevertheless, negative media narratives of immigrants burdening welfare services have exacerbated public hostility (Arai, 2005). Unfamiliarity with cultural norms, poor English proficiency and poverty negatively impact diagnosis and intervention of disabled children, suggesting a mutually dependent relationship between disability experience and migration experience (Scope and Equalities National Council, 2012). 
These contexts all affect the different levels of mean making that disability entails, shaping support available to disabled families and affecting schooling decisions. This research highlights the need for a holistic analysis of culturally Eastern individuals intersecting with a culturally Western environment, linking broader environmental contexts with individual experiences.

\section{Research aims}

This research aimed to provide nuanced understanding of the experiences, roles and attitudes of South Asian mothers towards their child's disability. The aim was to explore how mothers socially construct their roles, their understanding of disability and support and their expectations and concerns regarding schooling, absent from existing literature. The aim was to go beyond existing definitions of disability, by exploring participants' individual construction and understanding of disability based on their experiences.

The research focused solely on maternal perspectives, because in most cases, mothers are the primary carers of disabled children, as are the majority of participants in studies on parental experiences. It is incumbent on professionals to listen to maternal perspectives to understand the various roles these mothers occupy. Schools will only establish respect and transparency with mothers regarding children's overall outcomes, by acutely sensitising themselves to maternal needs and concerns.

\section{Methodology}

This research was informed by critical feminist views around the need for intersectional analysis incorporating multiple contexts and fluid positioning of participants. The Intersectional Framework was first proposed by Kimberle Crenshaw (1989), within feminist studies, and later extended to human rights and queer studies. Crenshaw argued feminist, race and sexuality studies 
advocated for individual groups but did not address hybrid identities (e.g., gay, Hispanic, workingclass woman). Therefore, this research has used the Intersectional Framework to gain a nuanced understanding of how migration experience, culture and religion affect South Asian maternal experiences of supporting a disabled child. Weber (2001) reveals how the Intersectional Framework examines social exclusion within race, class, gender and sexuality. Yuval-Davis (2006) suggests other forms of social exclusion such as disability studies ${ }^{3}$ would benefit from an intersectional analysis. Weber's (2001) systems for social exclusion are:

$1 \quad$ Historically and geographically/globally contextual

2 Socially constructed

3 Involve power relations

$4 \quad$ Have macro-social structural and micro-social psychological levels

5 Occur simultaneously

This research examined multi-layered citizenship and minority integration through the Intersectional Framework. It also allows consideration of central and peripheral macro and microfactors. Complex interview questions can be thematically framed, exploring how social divisions and maternal identity are constructed by multiple strands, as the fluidity of social constructs becomes apparent over time. This research consisted of five case studies providing in-depth descriptive accounts of five Pakistani immigrant mothers' understanding of their child's disability. These maternal accounts were developed through individual case studies, allowing examination of variances from case-to-case. Data were collected through semi-structured inter-views conducted in Urdu, the participants' preferred language. Repeat interviews could not be conducted due to time and cost limitations, so only key themes were covered in one-off interviews. Mothers permitted recording, translating and transcribing of interviews, after which recordings were erased

\footnotetext{
${ }^{3}$ Bjornsdottir and Traustadottir (2010) have critically explored the Intersectional Framework with regards to social inclusion of young adults with disabilities and the various macro-forces that affect their social participation.
} 
and participants' informed. All participants were offered copies of their transcribed interview, which one mother accepted.

\section{Access}

A secondary special school in an ethnically mixed town in northern England agreed to participate in the research. A sample incorporating Pakistani and Bangladeshi mothers was initially sought; however, Westchester School ${ }^{4}$ had no pupils from a Bangladeshi background. An introductory letter was sent detailing the research background and aims to all Pakistani mothers at the school, requesting interviews and permission to examine their children's school documents. Eight mothers initially agreed to participate, but non-availability reduced the final sample to five. The school, like gatekeepers, helped identified these mothers as potential participants making it difficult to ensure anonymity; however, all names were removed in the final report.

\section{Participants}

Three mothers originated from Mirpur-Azad Kashmir and two from Pakistan's Punjab Province. All five mothers were housewives by choice, and averaged 38 years of age. Four mothers were first-generation immigrants through transnational marriage, although one migrated with her parents in her youth. Four families were working class (including one unemployed spouse), and one family was lower middle class. On average, there were five people per household. (Tables 1 and 2 provide a brief summary of the participants' profile).

\section{Table 1: Participants' profile}

\footnotetext{
${ }^{4}$ The names of the school and all participants have been replaced with pseudonyms to protect confidentiality.
} 


\begin{tabular}{|c|c|c|c|c|c|c|}
\hline $\begin{array}{l}\text { Mother } \\
\text { Name }\end{array}$ & $\begin{array}{l}\text { Mother's } \\
\text { educational } \\
\text { level }\end{array}$ & $\begin{array}{l}\text { Country of } \\
\text { education }\end{array}$ & $\begin{array}{l}\text { Languages } \\
\text { spoken }\end{array}$ & $\begin{array}{l}\text { People per } \\
\text { household }\end{array}$ & $\begin{array}{l}\text { Disabled } \\
\text { individuals per } \\
\text { house }\end{array}$ & $\begin{array}{l}\text { Child's } \\
\text { Disability }\end{array}$ \\
\hline Saima & $\begin{array}{l}2 \text { year primary } \\
\text { schooling }\end{array}$ & UK & $\begin{array}{l}\text { English, } \\
\text { Punjabi, Urdu }\end{array}$ & 06 & 01 & $\begin{array}{l}\text { Degenerative } \\
\text { Disorder }\end{array}$ \\
\hline Hajra & $10^{\text {th }}$ Grade & Pakistan & Punjabi, Urdu & 05 & 02 & $\begin{array}{l}\text { Global } \\
\text { Developmental } \\
\text { Delay }\end{array}$ \\
\hline Batool & $5^{\text {th }}$ Grade & Pakistan & Punjabi, Urdu & 07 & 03 & Autism \\
\hline Amna & $8^{\text {th }}$ Grade & Pakistan & Punjabi, Urdu & 06 & 02 & Autism \\
\hline Rahat & No education & $\mathrm{N} / \mathrm{a}$ & $\begin{array}{l}\text { Punjabi, } \\
\text { Urdu }\end{array}$ & 02 & 01 & $\begin{array}{l}\text { Global } \\
\text { Developmental } \\
\text { Delay }\end{array}$ \\
\hline
\end{tabular}

Table 2: Participants' profile

\begin{tabular}{|lccllll|}
\hline $\begin{array}{l}\text { Mother } \\
\text { Name }\end{array}$ & Age & Child Age & $\begin{array}{l}\text { Country of } \\
\text { Origin }\end{array}$ & Ethnicity & Religion/ Sect & Profession \\
\hline Saima & 38 & 15 & $\begin{array}{l}\text { Pakistan- } \\
\text { Mirpur }\end{array}$ & $\begin{array}{l}\text { Pakistan } \\
\text { Punjabi }\end{array}$ & Islam-Sunni & Housewife \\
\hline Hajra & 39 & 13 & $\begin{array}{l}\text { Pakistan } \\
\text { Rawalpindi }\end{array}$ & $\begin{array}{l}\text { Pakistani } \\
\text { Punjabi }\end{array}$ & Islam-Sunni & Housewife \\
\hline Batool & 42 & 14 & $\begin{array}{l}\text { Pakistan } \\
\text { Jhelum }\end{array}$ & $\begin{array}{l}\text { Pakistani } \\
\text { Punjabi }\end{array}$ & Islam- Shia & Housewife \\
\hline Amna & 36 & 13 & $\begin{array}{l}\text { Pakistan - } \\
\text { Mirpur }\end{array}$ & $\begin{array}{l}\text { Pakistani } \\
\text { Punjabi }\end{array}$ & Islam- Sunni & Housewife \\
\hline Rahat & 36 & 13 & $\begin{array}{l}\text { Pakistan- } \\
\text { Mirpur }\end{array}$ & $\begin{array}{l}\text { Pakistani } \\
\text { Punjabi }\end{array}$ & Islam- Sunni & Housewife \\
\hline
\end{tabular}




\section{Ethics}

At the research design stage, the British Educational Research Association's ethics guidelines were followed, and a research ethics checklist was completed and submit-ted to the Graduate Board at the University of Cambridge. There was no intention for this research to generalise South Asian maternal experiences rather that maternal interpretations from the sample (or the interpretations of their under-standing) should not be mistaken as representative of all South Asians. Such generalisations can result in negative stereotypes affecting professional practice, such as professionals assuming South Asian families reject formal support due to informal support systems (Katbamna et al., 2004). Since this inquiry was grounded in the critical paradigm incorporating a minority viewpoint, it was imperative to highlight positives rather than reinforcing negatives.

The ethicality of consent forms was also questioned which increased ethical responsibilities because the participants were primarily not English proficient, risking suspicion, fear and misunderstanding (Sikes and Piper, 2010). This reveals participants' vulnerability towards researchers and the necessity of respecting their trust. Ensuring participant confidentiality was ethically essential but challenging because mothers had been highlighted by Westchester School. This issue was addressed by allocating pseudonyms to participants and discussing findings through relevant themes rather than individual cases.

\section{Analysis}

Data were analysed in the traditional pen-and-paper method without software, analysing documents and making points to probe in a research diary. In this way, data collection was combined with preliminary data analysis (Miles and Huberman, 1994). For instance, an unexpected but consistent theme emerging from interviews regarded children's referral to special 
school, which was then explored further through document analysis. New empirically driven codes were also introduced, intrinsically related to existing themes. When initially reading transcribed interviews, this conceptual list helped illuminate recurring themes across different interviews. Second-level coding was conducted after repeatedly reading each case, with interpretations added under descriptive codes. Finally, similarities, dissonances and exceptions across and within cases were considered; this helped improve cross-case analysis and increase the case studies' dependability.

\section{Findings}

Following analysis of data collected through interviews with Saima, Hajra, Batool, Amna and Rahat, three major themes were developed:

$1 \quad$ Understanding and perceptions of disability

2 School placement decisions and maternal experiences with professionals

$3 \quad$ Role of religion within parenting and supporting a disabled child

\section{Understanding and perceptions of disability}

Since their disabled children had reached secondary school age, mothers could provide retrospective and current under-standings and experiences of disability. Each mother (except Rahat) declared it was they who first suspected their child's delayed development rather than other family members. However, mothers were unsure whether medical reasons or cultural expectations had triggered their suspicions, which were formally confirmed at disclosure. Unsurprisingly, already having a disabled child influenced maternal experiences of disclosure. For instance, Batool had a son with autism before her daughter was born, while Saima did not: 
'I didn't feel it as much because I already had a son with autism'. - Batool

'The first time they heard this news was really stressful. . . because she's the first in my side and in my husband's side of the family who's like this.' - Saima

Mothers ostensibly rejected the diagnosis during disclosure even while accepting doctors as experts, because their notions of disability differ from medical definitions:

'We thank God our children can walk talk ... just by looking at them you can't say they're sick.' - Amna

This notion of looking disabled resurfaced repeatedly during interviews. Although this seemingly portrayed negative visual imagery of disability, mothers were referring to looking different to societal norms. Mothers wanted their children to be perceived as normal to protect them from noninclusive societal attitudes:

'As parents we are sensitive and aware that people are watching us ...'- Amna

Maternal reluctance to accept the diagnosis was also related to poor disclosure, and disregard for established procedure. Mothers had professional decisions thrust on them with disregard for their concerns and expertise. Three mothers' revealed doctors had not explained their child's slower progress:

'I don't think he [doctor] explained properly ... I did not understand why Alia was lagging behind.'- Batool

The continual assessment involved within disclosure exacerbated their uncertainty. Moreover, two mothers expressed distrust in doctors to varying degrees, affecting their confidence of disclosure: 
'The doctors don't know what her sickness is, they have just given a name autism ... they explain autism saying these children understand less, speak less.'- Amna

Rahat, who was not English proficient, was excluded from the disclosure process by her (then) husband and her in-laws. They hid her child's disability from her to avoid distress:

'The doctors asked my family if I knew what my daughter had ... as I had a happy expression on my face.' - Rahat

Rahat felt blessed having a daughter, her first child after 6 years of marriage, and was not distressed by Noor's disability which was just one aspect of her daughter's life. She was more upset when recalling the doctor had assumed she should be grieved by having a disabled child. Mothers claimed that doctors had assured them their children would gradually achieve typical development, except Saima whose daughter has a degenerative disorder. However, doctors sometimes shelter behind medical terms of disability, leaving families confused with unrealistic expectations of cure:

'The doctor said in $99 \%$ of cases children develop like this but become alright as they grow-up ... But time went on and it [progress] didn't happen ...' - Hajra

Mothers also thought disclosure related to physical and medical needs rather than intellectual development, illustrating their level of understanding and expectations of their children's progress at that time. All mothers suggested the term sickness best illustrated their understanding of their children's disability post-disclosure. Batool's daughter Alia has severe autism spectrum disorder (ASD):

'When she was one year old Alia wasn't talking ... she was tested [but] they said she too has got this sickness.' - Batool 
Diagnosis helps parents apply for additional resources, even if it means labelling the child. For example, disclosure feedback from Amna's husband in 2003 suggested diagnosis helped secure an ASD team to advise the school regarding their child. This reflects how widely medical labels are used within educational discourse, and that mothers realise their children will be better supported by using medical labels. Amna's Pakistani neighbours knew her daughter was dis-abled so never left her unattended. Other mothers reported community stigma but claimed it did not affect their every-day lives. However, they also admitted to curbing social contacts in case their child was treated differently, indicating societal attitudes did affect them:

'Our culture is bad. They know that your child is sick but still they make comments.' Hajra

Mothers found the permanence of their children's atypical cognitive development distressing. Their fears about their child's exclusion from the normal label were formalised by their children's referral to a special school:

'When she shifted to special school it was very difficult for me. [I] observed her, read her reports then I had to accept reality.' - Saima

Mothers wanted their children to learn independence at school at their own pace. For instance, Hajra was delighted when her son learnt to switch on a computer by himself, but she also recognised her son possessed jumbled speech, preferred silence and disliked unfamiliarity. Amna similarly reported her daughter's improvement through interaction at school, communicating better in English and counting up to 50. The type and severity of disability influenced progress. For example, Saima's daughter, Sehr, had a degenerative disorder and had gradually become a permanent wheel-chair user. Sehr's medical needs (greater than other children in this research) 
rightly dictated Saima's day-to-day experiences, explaining Saima's continued reliance on medicalised views. Hajra and Amna's experiences incorporated social constructions of disability because they were less dependent on medical professionals as their children grew up. Gender also influenced the conceptualising of disability for some mothers. Four mothers had daughters attending Westchester School, and one mother only had sons. Amna displayed gendered views regarding her daughter's disability, valuing Kiran's education less than her son (who also had ASD) and cultural expectations of performing domestic chores:

'With my daughter, I thought she would do housework with me. I didn't want a mainstream school for Kiran, but I wanted my son to go to a normal school.'- Amna

When asked why she replied:

'If he plays with sick children he'll behave like them.'- Amna

The other mothers with daughters at Westchester School displayed less gendered perceptions. Still, they were reluctant to send their daughters on overnight trips despite school requests for parental support, fearing community criticism and gossip about their daughters' reputations, indicating strong cultural influences affecting gendered perceptions.

'You know how it is to send your daughter alone ... Pakistani people don't like this, so I don't do this.'- Rahat

'Daughters and sons have different issues. A lot of things come to mind ... she isn't aware of who changes her.' - Batool

It was difficult to separate gendered beliefs from natural maternal protectiveness for their children from community scrutiny of disability, gender or both. 


\section{School placement decisions and maternal experiences with professionals}

The influences shaping children's overall education experiences were the second major research theme. All mothers praised special schools, but only Amna specifically chose a special school placement; the other mothers initially opted for mainstream placements. At mainstream nurseries, these children were assessed for primary special school admission, which families found distressing. Mothers recalled their children's placement was influenced by:

1 Mainstream primary school's child development targets and its resource availability

2 Social workers' advice

3 Doctors' input

Unfamiliarity with special schools worsened their anxiety, as to them a special school indicated segregation. Mothers favoured mainstream placement because they wanted a normal school life where their children may benefit from the company of typical peers:

'All the children her age were going to normal schools ... why can't she go there as well?' - Saima

'When he starts school he'll pick up by playing with normal children of his age. Children learn from each other.' - Hajra

Four mothers had mainstream placement requests rejected; incidentally, this was because of inadequate one-to-one support rather than any potential negative impact of disabled children on typical peers. Social workers and doctors pressed parents towards special schools, even appearing to give expert medical opinion on educational matters. Amna had requested mainstream school for her younger son with ASD: 
'The doctor said, send him to a special school not a normal school because he won't get as much support there.' - Amna

Hajra's son, Imran, had been bullied previously so she felt special schools may offer greater protection:

'In primary school, children are children they hit other children and move on ... if someone bullied him he wouldn't know who it was.' - Hajra

Professionals accentuated Hajra's existing concerns about bullying and inadequate one-to-one support within main-stream schools to influence her placement decision. After visiting special schools, negative maternal preconceptions were dispelled; mothers found teachers could be more invested and caring with children:

'There are more facilities, the teachers know what specialist attention Sehr needed ... so the school was right for her. . they let her learn at her own pace.'- Saima

Placement decision-making emerged as the moment mothers first conceptualised their child's disability as a learning difficulty, notwithstanding the professional coercion. English proficiency regulated maternal experiences with professionals; four mothers were not English proficient so spouses managed professional interactions, despite mothers being the main decision-makers for their children. Except for Rahat during her disclosure experience, mothers did not feel marginalised during these interactions. Westchester School suggested these mothers were 'nice and supportive' but were disengaged from the school. However, parents with children at secondary special schools often reduce involvement, having developed the self-confidence to trust professionals (Murray, 2000): 
'Before the school would explain to me about sign language or symbols ... now when they ask me I know from experience it's what she [Alia] needs.'- Batool

Mothers happily relied on teachers for expert support for their children, aware someone was always available to resolve issues:

'I know the school looks-after her. Whatever steps they have taken, it's for her betterment.' - Saima

'I don't doubt they'll do their job properly, they do more than we do.' - Hajra

Reduced involvement at school coincided with increased involvement with social workers because of post-19 provisions and disability allowances. Three mothers had two or more disabled children, which coupled with housing and welfare needs, required the active involvement of social workers. Mothers often worked with multiple social workers, developing asymmetric relationships which lowered their expectations and their bargaining power. For instance, Amna recalled poor experiences with three social workers, only getting assistance when Kiran was 10 years old. Only Saima maintained professional medical interaction because of her daughter's degenerative condition. Being English fluent, she was confident accessing information and interacting directly with professionals.

All children in this research were 13-15 years old, so mothers were concerned about post-19 funding, employ-ment prospects, post-parental care, child protection and independence skills particularly because of recent changes to UK SEN policy:

'They’ve stopped giving disability allowances after 19. What will I do then? Keep him at home all day?'- Hajra 
Hajra worried about future employment opportunities being the only mother with teenage sons; mothers with daughters were unconcerned with this, reflecting gendered expectations. Mothers with more than one disabled child suffered greater uncertainty than mothers with one disabled child; Saima was unconcerned about her daughter's future provisions, while Batool and Hajra were apprehensive about their children's future. Mothers were concerned about future caregiving responsibilities, since they did not use formal or informal networks. Although all mothers could look after their children now, they were concerned whether their health would allow them to continue in the future.

'After we are gone, how will Kiran be looked-after? There will be a time when I cannot do this anymore, so who will do it?' - Amna

Ultimately, mothers said they would continue to care for their children into adulthood. Disregarding residential placement, mothers hoped the government would continue supporting children at home. As their children reached puberty, mothers were also concerned about sexual abuse. Mothers with daughters were hesitant about overnight school trips; interestingly, the deputy head revealed Westchester School had not under-stood why parents were reluctant. Mothers were acutely aware their children lacked understanding of right and wrong, being easy targets for abuse:

'With daughters you're always concerned someone doesn't take advantage of her.' Batool

Independence was another future concern. It was more difficult supporting children in their daily routines as they grew up. Mothers wanted children to gain independence skills to ease their transition into adulthood.

\section{Role of religion within parenting and supporting a disabled child}


Religion formed a major theme within this research, affecting three major aspects of the mothers' lives:

$1 \quad$ Role of parenting

2 Coping mechanism

3 Beliefs about the child's disability

Islamic theology directly links parental accountability for their children to salvation in the hereafter. Mothers perceived parenting their disabled children was a divine test of their parenting skills:

'God only gives these real-life exams to people who can bear it. Our place in heaven is guaranteed.'- Hajra

'God wills we work hard with them. We'll be rewarded on Judgement Day.' - Amna

Islam advocates the immanence of parental rights and responsibilities in their everyday lives. Some Islamic scholars believe parenting is life's most important duty (Hamdan, 2009). Although parenting as a religious obligation cannot be directly attributed to antipathy to residential care, parents may view formal care as escaping responsibility:

'She is my gift I don't want to leave her to somebody else.' - Saima

'I pray God gives me strength so I can do this myself and don't have to ask anyone for help.' - Hajra

Mothers suggested God was testing their gratitude for being blessed with children:

'God is testing to see if we're good parents, how we look-after them.' - Rahat 
'There are people who can't have children. Whatever God has given me, I'll happily accept His decision.'- Batool

The mothers' positive religious beliefs did not lessen the realities of life. But accepting God's will made mothers explore every opportunity to better their child's outcomes, to pass the parenting test. Religion was also a positive coping mechanism for mothers, ranging from an almost inconspicuous use of Inshallah (if God wills) and Mashallah (by the grace of God), to believing God gives strength to cope, to ritually reciting Quranic verses to transform water into divine medicine:

'Pray to God for strength. Worrying won't solve your problems. Having the will to do things will solve your problems.' - Batool

Mothers did not report mental health problems from sup-porting their disabled children. However, they enjoyed strong spousal and family support, which combined with their faith, helped them cope. Moreover, having teenage children possibly meant the stress experienced during dis-closure or placement was forgotten.

Initially, mothers described their children's disability in diagnostic terms, or symptoms resembling their child's statement. There were no theological explanations:

'She can't understand like other girls her age. She is mentally behind.' - Rahat Only when religion was specifically probed did mothers proffer religious explanations, describing their children as blessings; no mother described her child as divine punishment. Mothers were asked: How does religion shape your understanding towards your child's disability? They responded:

'Whatever God has given me, I am happy.' - Rahat 
'We've been blessed with such obedient sons who look-after her [Sehr]. As a reward God has given my sons good education.' - Saima

Overall, religion was a dominant theme but was interlinked with parental rights and responsibilities, coping mechanisms and as a viewpoint of disability.

\section{Concluding discussion}

Weber (2001) notes every experience in the Intersectional Framework is marked by race, class, gender and sexuality which determine the status and treatment of minority groups in social relationships. Disability was incorporated into this framework to enhance understanding. Mothers did not believe disability directly disadvantaged them, but they recognised disability placed professionals in a higher social category than them. For instance, parental dependence on teachers for educational outcomes gave the impression that teachers had greater knowledge about their children.

Enforced placement decisions were the mothers' first experience of them versus us (Hess, Molina and Kozleski, 2006). Medical and educational experts robustly persuaded parents during primary placement that special schools would best support their children, including heightening concerns about bullying within mainstream schools. Mothers accepted placement decisions as 'expert opinion' without appeal, reflecting how professionals exercise social control through expert authority. But professional interactions also enabled mothers to develop new constructs of disability and appreciate special schools. Initial preferences for mainstream placement reflected parental hopes for inclusion. Once placement decisions were made, mothers embraced the inclusive attitudes within special schools. As children transitioned from primary to secondary 
school, cultural and gendered expectations shaped children's schooling experiences, like excluding daughters from overnight school trips.

Historical and geographical contexts also surfaced within interviews. Mothers weighed up the support available as immigrants within the UK compared to Pakistan. For some, this decision was straightforward, although others realised this through accumulated lived experiences. For example, Saima settled in Pakistan after her marriage but returned to the UK after experiencing non-existent provisions in Pakistan. There is no universal explanation of maternal understanding. No two maternal responses were identical because mothers understood their experiences differently, reflecting different social constructs at different times. During early years following disclosure, disability was understood in pathological terms, influenced by professional medical interactions; but this is not limited to South Asian mothers. As children reached school age, educational practitioners played a greater role, although some parents maintained medical interaction if their child had complex medical needs. During secondary years, religious beliefs, specifically around parental rights and responsibilities helped mothers understand their disability experiences. The framework revealed how South Asian cultural and gendered perceptions influenced mothers' educational and schooling decisions. Hajra, the only mother with teenage sons who were disabled, voiced future employment concerns while mothers with daughters worried about negative societal influences. Mothers referred to South Asian culture from an outsider's perspective, suggesting it was sometimes burden-some and stigmatising.

The Intersectional Framework highlighted different processes simultaneously shaping maternal understanding and support. This research highlighted that understanding of disability evolves as the child progresses. Maternal responses suggested an amalgam of factors shaped their past and current understanding. Disclosure, special school placement and professional interactions all 
significantly shaped earlier perceptions of their children's disability. However, as their children grew up, a religious understanding of parental responsibilities, family networks and support groups gained prominence. The Intersectional Framework established a bi-directional relationship between the conceptualisation of disability and children's schooling experiences. Conceptualising disability as a learning difficulty enabled mothers to accept that special schools better suited their children. Interacting with educational professionals helped mothers understand and support their children at home. For example, Batool said after-school support improved Alia's behaviour at home by following set routines.

The Framework revealed unwitting evidence of how macro and micro-factors affected their experiences. For instance, UK industrial expansion in the 1960s offered factory jobs to immigrant men; deindustrialisation in the 1980s reduced demand for skilled manual labour. Batool and Hajra's standards of living fell when their husbands lost their factory jobs, leaving one unemployed and the other working as a taxi driver limiting their resources. Thus, their daily experiences and their future expectations were deeply entwined with their socio-economic status.

Most interestingly, religion emerged as a powerfully positive tool which mothers used to understand their parenting roles and broader experiences of disability. Despite studies about negative religious interpretations of disability, this research supported Shah's (1995) argument that such negative stereotypes are not representative of all South Asians. Some mothers suggested their child was a 'divine gift'; however, they may not have been alluding to disability. Research suggests parents across different faiths and cultures perceive typical children as a blessing (Godina, 2012), and would be interesting for any comparative analysis of typical and disabled children to examine. Schools such as Westchester could incorporate religion and spirituality into establishing parent support groups to increase their relevance and encourage participation. 


\section{Methodological limitations}

This research reported first-hand maternal accounts about their previous and current experiences of supporting dis-abled children; therefore, any conclusions must be tentative since they are based on self-reported retrospective data, which may affect the authenticity of the accounts. In addition, all research participants were from rural Punjab in Pakistan. Ideally, the sample would also have included Bangladeshi mothers; mothers from urban Pakistan or other Pakistani provinces would also have broadened the research context. The sample consisted of working-class house-wives; a different power relationship with professionals may have entailed if the sample had included middle-class working mothers. Including mothers of typical children would have enabled examination of whether South Asian girls' education generally is influenced by gendered perceptions. Blacher et al. (1997) included mothers of typical and non-typical children, which encouraged clarity when attributing disability as a determining factor. Time and cost constraints restricted follow-up interviews, limiting the themes that could be pursued. Time constraints restricted the development of a deeper rapport with participants which may have resembled insensitivity at times, particularly when inquiring about whether experiences of their own segregated education influenced the mothers' expectations of their children's education. Two mothers were hesitant to discuss their schooling, ethically precluding further questioning. What remained unsaid by mothers might have been important determiners of decisions made for their disabled children, but the findings reflected only what could be pursued.

\section{Implications}

With few major UK studies on ethnic disproportionality within special education (Strand and Lindsay, 2012), there is scope to uncover how ethnic minorities understand educational jargon and implications of SEN, which ultimately impacts their relationships with schools and broader dis- 
ability experiences. Several key themes in this research require further consideration, like the role of gender within educational decision-making. This research showed gender plays a significant role within South Asian culture in how schooling and placement decisions occur. A larger more heterogeneous sample of mothers, with daughters and sons in equal ratio, and from different social and ethnic backgrounds would be preferable. In addition, further exploration of which factors influence mothers in their placement decisions is warranted. For instance, Amna's choice for special school placement initially seemed deeply rooted in gendered expectations, but other factors like better one-to-one support also came into play.

\section{Acknowledgements}

The author would like to acknowledge the close supervision and support from Dr Nidhi Singal during this research and to Prof. Anthony Feiler, Helen Knowler and Reza Rizvi for their proofreading and feedback for this paper.

\section{References}

Abbas, T. (2004). The education of British South Asians: Ethnicity, capital and class structure. Hampshire: Palgrave Macmillan

Abbas, T. (2007). 'Muslim minorities in Britain: integration, multiculturalism and radicalism in the post-7/7 period'. Journal of Intercultural Studies, 28(3), pp.287-300.

Feiler, A., Porter, J., Daniels, H., Georgeson, J., Hacker, J. and Martin, S. (2012). 'The use and usefulness of a parent questionnaire to help schools identify disability'. Journal of Research in Special Educational Needs, (12), pp. 22-27. doi: 10.1111/j.1471-3802.2011.01199.x 
Arai, L. (2005). Migrants \& public services in the UK: a review of the recent literature. Compas.

Bell, J. (2010). Doing your research project. McGraw-Hill International.

Bhatti, G. (1999). Asian children at home and at school: An ethnographic study. London: Routledge

Bjornsdottir, K. and Traustadottir, R. (2010). Stuck in the land of disability? The intersection of learning difficulties, class, gender and religion. Disability \& Society, 25(1), 49-62

Blacher, J., Lopez, S., Shapiro, J. \& Judith, F. (1997). 'Contributions to depression in Latina mothers with and without children with retardation: Implications for caregiving'. Family Relations, 46(4), pp.325-334

Blinder, S. (2012). Settlement in the UK. The Migration Observatory, Oxford: University of Oxford

Bywaters, P., Ali, Z., Fazil, Q., Wallace, L.M. and Singh, G. (2003). 'Attitudes towards disability amongst Pakistani and Bangladeshi parents of disabled children in the UK: Considerations for service providers and the disability movement'. Health and Social Care in the Community, 11(6), pp.502-509

Croot, E.J., Grant, G., Cooper, C.L. \& Mathers, N. (2008). 'Perceptions of the causes of childhood disability among Pakistani families living in the UK'. Health and Social Care in the Community, 16(6), pp.606-613

Crozier, G. (2009). South Asian parents' aspirations versus teachers' expectations in the United Kingdom. Theory Into Practice, 48(4), 290-296. 
Crozier, G., \& Davies, J. (2006). Family matters: a discussion of the Bangladeshi and Pakistani extended family and community in supporting the children's education. The Sociological Review, 54(4), 678-695.

Department for Education and Science (DES) (1981). The Education Act 1981. London: HMSO

Department for Education and Employment (1994) Code of Practice for the Identification and Assessment of Special Educational Needs. London: DfEE

Department for Education and Skills (DfES). (2001). Special educational needs code of practice. London: DfES

Department for Education. (2012). Draft Legislation on Reform of Provision for Children and Young People with Special Educational Needs (Vol. 8438). The Stationery Office

Fazil, Q., Bywaters, P., Ali, Z., Wallace, L. \& Singh, G. (2002). 'Disadvantage and discrimination compounded: The experience of Pakistani and Bangladeshi parents of disabled parents in the UK'. Disability \& Society 17 (3), pp.237-253

Godina, L. (2012). 'Religion and parenting: Ignored relationship?' Child and Family Social Work Gonzales, N., \& Moll, L. C., \& Amanti, C. (Eds.). (2005). Funds of knowledge: Theorizing practices in households, communities, and classrooms. Mahwah, NJ: Erlbaum.

Gottlieb, R. S. (2002). 'The tasks of embodied love: moral problems in caring for children with disabilities'. Hypatia, 17(3), pp. 225-236.

Hamdan, A. (2009). Nurturing eeman in children. Saudi Arabia: International Islamic Publishing House 
Hatton, C., Akram, Y., Robertson, J., Shah, R. \& Emerson, E. (2003). 'The disclosure process and its impact on South Asian families with a child with severe intellectual disabilities'. Journal of Applied Research in Intellectual Disabilities, 16, pp.177-188

Hatton, C., Akram, Y., Shah, R., Robertson, J. \& Emerson, E. (2004). 'Supporting South Asian families with a child with severe disabilities'. London: Jessica Kingsley Publishers

Heer, K., Rose, J. \& Larkin, M. (2012). Understanding the experiences and needs of South Asian families caring for a child with learning disabilities in the United Kingdom: An ExperientialContextual Framework. Disability \&Society, 1-15

Hess, R. S., Molina, A. M., \& Kozleski, E. B. (2006). 'Until somebody hears me: Parent voice and advocacy in special educational decision making'. British Journal of Special Education, 33(3), pp. $148-157$.

Katbamna, S., Ahmad, W., Bhakta, P., Baker, R. \& Parker, G. (2004). 'Do they look after their own? Informal support for South Asian carers'. Health and Social Care in the Community, 12(5), pp.398-406

Kenway, P. \& Palmer, G. (2007). Poverty among ethnic groups- how and why does it differ? Joseph Rowntree Foundation, York: New Policy Institute

Miles, M.B., \& Huberman, A.M. (1994). Qualitative data analysis: An expanded sourcebook (2nd ed.). New-bury Park, CA: Sage.

Murray, P. (2000). 'Disabled children, parents and professionals: partnership on whose terms?' Disability \& Society, 15(4), pp.683-698. 
Office for National Statistics, UK. (2013). Migration Statistics Quarterly Report, May 2013. Retrieved from http://www.ons.gov.uk/ons/rel/migration1/migration-statistics-quarterlyreport/may-2013/index.html

Scope and Equalities National Council (2012). Over-looked communities, over-due change: How services can better support BME disabled people. London: Scope

Shah, R. (1995). The silent minority-children with disabilities in Asian families. London: National Children's Bureau

Shakespeare, T. (2008). Debating disability. Journal of medical ethics, 34(1), 11-14.

Sikes, P. \& Piper, H. (2010). Ethical research, academic freedom and the role of ethics committees and review procedures in educational research. International Journal of Research \& Method in Education, 33(3), 205-213

Strand, S., \& Lindsay, G. (2012). Ethnic disproportionality in the identification of speech, language and communication needs (SLCN) and autism spectrum disorders (ASD). London: DfE

Strand, S. \& Lindsay, G. (2009). 'Evidence of ethnic disproportionality in special education in an English population'. Journal of Special Education, 43(3), pp.174-190

Ward, K., Amas, N., \& Lagnado, J. (2008). Supporting disabled refugees and asylum seekers: Opportunities for new approaches. London, Metropolitan Support Trust

Warnock, M. (1978). Special educational needs: Report of the Committee of Inquiry on the education of handicapped children and young people. London: HMSO.

Weber, L. (2001). Understanding race, class, gender and sexuality: A conceptual framework. Boston: McGraw Hill 
Yuval-Davis, N. (2006). Intersectionality and feminist politics. European Journal of Women's

Studies, 13(3), 193-209 